\title{
Empowerment Media Literacy Education and Cultural Safety and Cultural Heritage of Ethnic Minorities
}

\author{
Hao Qiu \\ Yunnan Normal University \\ Kunming, China 650500
}

\begin{abstract}
In the context of the current mediating society, cultural penetration presents a tendency of "hiddenization". The problem of cultural safety and inheritance of ethnic minorities has become an important issue in the social development of ethnic minorities. The empowerment media literacy education would enhance the media literacy of ethnic minority groups. It is of great significance in safeguarding the cultural safety of ethnic minorities and passing on the national culture.
\end{abstract}

Keywords-empowerment media literacy education; ethnic minorities; national cultural security; national cultural heritage

\section{INTRODUCTION}

Since the beginning of media literacy education, it has gone through several paradigms of immunity - screening - criticism - empowerment. The goal of empowerment media literacy education is to develop the skills of analysis, speculation, communication, and self-expression of educated people. And then, it would achieve self-development and the development of society. In the context of the current mediating society, cultural penetration has shown the tendency of "hiddenization". The problem of cultural safety and inheritance of ethnic minorities has become an important issue in the social development of ethnic minorities. Therefore, it is particularly important for minority groups to actively and effectively use the mass media and launch corresponding national cultural communication activities. And it could maintain national cultural security and inherit national culture. Then, it would achieve self-development and national culture development.

\section{The EVOlUtion AND DEVELOPMENT OF MEDIA LITERACY EDUCATION}

The concept of media literacy and educational practice is historical, cultural and social complex system that has evolved along with the evolution of human history, the changes of culture, and the development of society. There are different expressions of media literacy in different historical periods, cultural contexts, and social environments. And the key cognition of media literacy is relatively consistent. That is the knowledge, skills, and abilities needed to use and deconstruct media information. The essence of related education is to guide people to correctly handle the relationship with the media. The paradigm of media literacy education experienced four shifts in different periods.

\section{A. Immune Paradigm}

In the western societies of the 1930s, advances in printing technology enabled books to be accessible to ordinary people. The public newspapers would be more developed than that in the previous period. With the advancement of urbanization, the facilitation of transportation and the improvement of the general public's knowledge, popular audiences have emerged. At the same time, in the UK, the mass newspaper industry has achieved a leap-forward development. However, with this social phenomenon, there is a serious tendency toward vulgarization in the popular newspapers. The disseminated contents and values are related to traditional culture and orthodox education. It began to appear the differences. In 1944, as elite, the Frankfurt School put forward the theory of cultural industry. And they have made a profound critique of the commercialization of popular culture. Among these theories and doctrines, elite scholars generally regard the audience as a group of people who have no antibodies in front of the "viruses" spread by the vulgar media. To protect the country's outstanding traditional culture, it is necessary to nurture the resistance ability to keep away from the negative effects on popular culture. The media literacy education paradigm during this period was called the "immune paradigm."

\section{B. Screening Paradigm}

In 1945, the World War II was over. People's lives have become increasingly stable. The television technology has developed rapidly. With the electronic media occupying an increasingly prominent position in the cultural industry in the 1950s, television and movies have also become an important part of the cultural industry. Popular culture continues to engulf people's autonomy under business logic. And it also shows the positive effects. Originating from the 1960s, the British school of cultural studies was dissatisfied with the completely elitist position of the Frankfurt school. Based on the critical succession of the Frankfurt School's research results, it is more inclined to regard popular culture as the 
culture grown from the bottom of the masses. Also, it focuses on the power of cultural production and the creativity of the audiences. In this period, media literacy education focuses on using the audience's daily cultural experience of the media to educate them. It does not allow the audience to unilaterally reject the content of media communication. It focuses on teaching them the basis to make the distinction between high-quality culture and inferior culture. And then, they could make the choices. In this stage, the media literacy education paradigm is called the "screening" paradigm.

\section{Critical Paradigm}

In the period of Frankfurt school, the critical social perspective allowed them to begin to pay more attention to ideology. In Adorno's view, the cultural industry represented by the mass media performed the function of ideology in a way that people did not perceive. It can operate the entire capitalist society smoothly. British cultural studies also began to shift from the original aesthetic criticism to political criticism. In the 1960s, Hall learned nutrition from semiotics and Gramsci's ideology theory, and put forward the famous coding-decoding theory. He believes that the process of decoding and accepting popular culture is very complicated. It includes the effect of ideological intervention on the meaning coding of mass media, the resistance, elimination and reconstruction of the ideological structure of the audience in the process of decoding. The main purpose of media literacy education during this period was to teach the audience not to understand the media information unilaterally. It must combine specific social and historical contexts. And the rules used in the process of encoding and decoding would be affected by multiple factors.

\section{Empowerment Paradigm}

The "empowerment" theory is constructed from a series of core concepts such as "no power", "disempowerment", and "empowerment". And its core is power. Power represents the ability. It is powerful force for controlling and developing one's own living space. And any opportunity that prevents individuals from exercising one's decision-making or self-control over one's living space is the shortage of power. [1] The absence of power is an objective state of lacking ability or resources. It also includes the subjective feelings of individuals. The shortage of personal ability and resources will lead to individuals subjectively forming a sense of powerlessness. And then, they would lose the motivation to exercise decision-making or self-control over their own living space. It has seriously influenced individual development and participation in the social construction capabilities.

There are many ways to achieve the empowerment. And some scholars have studied on this point. Li Fengqin studied the development of minority women (2011). Based on the relevant research of other scholars, it has summed up the three ways, namely, individual empowerment, social empowerment and institutional empowerment. [2] The "individual empowerment" emphasizes the improvement of the individual's ability to live and influence the social environment, pays attention to the control of the individual's subjective psychology, the improvement of self-evaluation and satisfaction, and the improvement, change of the environment and self-action. [3] Social empowerment emphasizes the promotion of external forces in the process of empowerment, and advocates activating the subject of vulnerable groups through external forces. And it would achieve the goal of sustainable empowerment through the continuous circulation and construction of the interaction between the object and the subject. [4] "Institutional empowerment" believes that enhancing the ability to identify or protect oneself is not enough for the disadvantaged. It must have a formal system to protect its rights and interests. And only the country can afford and protect this environment. [5] In the aspect of social empowerment, "education empowerment" is considered to be an effective way to enhance individual capabilities through external forces. Through education, individual scientific and cultural literacy and the individual's required skills (including the use of media skills) are improved. Thereby, it would achieve the goal of empowerment.

In the late 20th century, computer technology was widely used. And the living environment and space of humankind began to undergo tremendous changes. The digitalization of information and the globalization of communication formed diversified media environment, social environment and cultural environment. The new Internet technology not only provides people with new means of communication, but also profoundly changes the way people conduct cultural communication and information dissemination. Its influence also radiates political, economic and other fields. The network participates in the construction of popular culture in completely new way. And it quickly forms a new type of "participatory culture" characterized by the empowerment. It began to generalize the main body of communication. And the elite discourse was deconstructed. During this period, media literacy education began to shift to the "empowerment" paradigm.

\section{THE IMPORTANCE OF EMPOWERMENT MEDIA LITERACY EDUCATION IN SAFEGUARDING ETHNIC CUltural SECURITY AND INHERITING NATIONAL CUltuRE}

\section{A. The Empowerment Media Literacy Education Plays a Role in Safeguarding the Cultural Safety of Ethnic Minorities and Inheriting National Culture}

The significance of the empowerment media literacy education is that it affirms the human subjective value, can promote active development of the society in which it lives, and enables the individual to form critical social environment and analytical understanding. In turn, it could foster the ability to construct the society in which it is located.

With the advent of mediated society, border minority areas are also increasingly surrounded by images of media production. However, the media literacy of frontier ethnic minority groups is generally low. This makes our media literacy education must be different from other groups in terms of their stages. We must gradually make advancement from the media cognition. In practice, special consideration 
should be given to the social psychological mechanisms and conditions affecting the group's media cognition and action abilities. And the methods of empowerment media literacy education should be applied. It should take full account of their indigenous and local knowledge. Based on the group's special culture needs, it should come up with the content and form of creative design media education. It is carried out in a bottom-up way. With their promotion of media literacy, they can nurture the subject consciousness of the local ethnic minority groups and help them solve the problems of ethnic development while developing themselves to a large extent.

At present, in the tide of globalization, the frontier ethnic minority areas are faced with the influence of foreign cultures. Their cultural safety issues and the inheritance of ethnic cultures have become prominent problems in the development of the nationalities. We must safeguard the security of national culture and inherit the national culture. And then, it can promote the development of the national culture. The improvement of national cultural soft power promoted by the development of national culture will provide the greatest contribution to the development of the regional economy, which in turn will promote the maintenance of the cultural security of the nation and the inheritance of the national culture. This is a virtuous cycle of development.

\section{B. The "Hidden" Tendency of Cultural Infiltration in the Process of Globalization Has Left Ethnic Minorities Facing the Problem of the Lack of Empowerment Media Literacy Education while Safeguarding National Cultural Security and Inheriting National Culture}

The cultural security of the country refers to the dominant cultural value system of sovereign nations, as well as the main cultural elements such as social life systems, language symbol systems, knowledge traditions and religious beliefs established on them, which are free from the erosion and destruction of internal or external hostile forces. And it will ensure that sovereign countries enjoy full and complete cultural sovereignty. They have cultural system that is in harmony with the political and economic development of the country. And they should maintain a high degree of national cultural identity among the people. [6] The cultural security of ethnic minorities refers to the security of cultural resources owned by 55 ethnic minorities other than the Han nationality in China. Safeguarding the cultural safety of ethnic minorities means protecting the cultural heritage, behavior, and values of ethnic minorities in China. The cultural roots will not be shaken by external shocks or intrinsic factors. The ethnic minorities have their own cultural identity and cultural characteristics. And then, they would achieve the "security".

The wave of globalization has brought about the cultural integration. When different national cultures enter new process of integration, ethnic minority cultures may face the impact of strong foreign cultures. The penetration of strong culture generally presents the tendency of "recessivation". It is attached to all kinds of cultural carriers. It has resorted to the emerging mass media in its means. And the rapid development of new media has penetrated into people's ideology, clothing, food, housing and other aspects. Its influence on people is subtle. And it is far more profound and huge.

Frontier ethnic minority areas have a low degree of social development. Although local residents are surrounded by media images, media literacy is generally low. Media literacy education still stays at the paradigm of immunization. Faced with the lack of empowerment media literacy education, ethnic minorities are maintaining national cultural security and inheriting ethnic culture.

\section{TO USE EMPOWERMENT MEDIA LITERACY EDUCATION TO ENHANCE ETHNIC MEDIA LITERACY, SAFEGUARD CULTURAL SAFETY OF ETHNIC MINORITIES, AND INHERIT NATIONAL CULTURE}

Based on the above analysis, it is easy to see that under the current background of globalization and the mediated society, minority groups urgently need to upgrade their media literacy. The promotion of media literacy could help them to discriminate media information. It is of great significance to use the mass media to maintain the safety of national culture, pass on and develop national culture. Specifically, we can develop it from the following aspects:

\section{A. To Creatively Design the Content and Form of Media Literacy Education, Promote Ethnic Minority Groups to Maintain the Cultural Safety of the Ethnic Group and Inherit the National Culture}

Empowerment media literacy education will be committed to effectively guiding the participation of people in the design of media content from the cultural experience of the local people and the actual development of ethnic cultures. It should help them understand and use the media, participate in self-development and the development of ethnic culture. Based on this point, it would have tangible impact on the protection and inheritance of the local ethnic minority culture.

On this point, the "participatory video" activities currently being conducted in some rural areas have brought us useful inspiration. On the basis of giving farmers full access to the cameras, they would have basic understanding of this medium in entertainment. They are trained in their shooting skills and guided to understand the communities in which they live. They should learn to discover the problems and participate in the production and dissemination of images of their lives. They should express themselves creatively with cameras, engage in community discussion, promote self-development and solve the problems of the community. In the same way, for minority groups, when choosing the empowerment media literacy to safeguard their cultural safety, pass on ethnic culture, and develop national culture practices, we must also consider the specific environment in which ethnic minority audiences are located and find regional differences. And then, we could choose the right way to do it. Specifically, we should regard the development of their national culture as a process. In this process, it should emphasize the participation of local audiences. They can participate in the dissemination of 
national culture and the maintenance of cultural security. It should seek their opinions and suggestions, learn and use their local knowledge and experience, cultivate their sense of responsibility, and guide them to make their own contribution to the development of their own national culture.

\section{B. To Adopt Interactive Education Model Centered on Ethnic Minority Members}

The interactive education model emphasizes learning in action, values the cultural interests of ethnic minority members, and emphasizes the corresponding education approach in the specific context rather than seeking universal law.

In the process of empowering media literacy education, we must pay attention to the changes in the cultural environment and the current social environment of ethnic minority members. We should understand the use of media literacy, media literacy knowledge and media analysis capabilities. And we should actively invite them to participate in the construction of media literacy content with their own experience. In the process, they discuss their own national cultural security issues and national cultural heritage problems. They also discuss the ways of communication to solve these problems. This kind of education way emphasizes to jump out of the traditional educator-based education way. It thinks over the problems from the perspective of minority members. The minority members should take the initiative to use the medium to maintain the national culture security and and inherit the development of national culture consciously and actively. And then, it would constantly enhance the ability.

\section{To Cultivate "Opinion Leaders" of Ethnic Minority, Increase the Dissemination of Ethnic Minority Cultures, and Optimize the Effects of the Dissemination of Ethnic Minorities}

The above-mentioned empowerment media literacy education would obtain certain actual effects. In order to promote the national minority culture security and the dissemination and the development of national culture, it needs to train those who have a relatively higher level of media awareness than the audience of ordinary minorities as "opinion leaders". It could indirectly affect the family and the surrounding people through them. These "opinion leaders" must be able to use the mass media to tap and disseminate the culture of their own ethnic areas. The majority of the audience can learn information about their national culture. Based on this point, it could expand their cultural influence and use the mass media. And then, the nation's culture could "go out".

\section{CONCLUSION}

The empowerment media literacy education has the distinct characteristics of guiding media users to increase their own power by actively participating in the production of media information. And they would constantly improve themselves and participate in social development. Frontier minority groups are located in remote areas. Their ability to strive for self-development and national development of resources and opportunities is also weak. The ability of using mass media to maintain national cultural security and inherit national culture is also weak. Empowered media literacy education promotes the critical thinking and self-efficacy of minority groups through bottom-up media literacy education. On this basis, the mass media can be effectively used to maintain the national cultural security and to inherit and develop the national culture.

\section{REFERENCES}

[1] Chen Shuqiang. Empowerment: A new perspective of social work theory and practice[J].Sociological Research. 2003( 5).

[2] Li Fengqin. Study on the development of ethnic minority women from the perspective of "Empowerment Theory" [J]. Journal of North Minzu University, 2011(4).

[3] Li Anhui. The development of ethnic minority women and the pursuit of political civilization [J]. Journal of Wuhan Institute of Science and Technology, 2006(12).

[4] Kamla Guptal , P.Princy Yesudian . Evidence of women's empowerment in India: a study of socio-spatial disparities [J]. GeoJournal. 2006( 65).

[5] Fan Bin. The empowerment of vulnerable groups and the choice of their models[J]. Academic Research, 2004( 12).

[6] Shi Zhongying. On national cultural security [J]. Beijing Normal University. 2004 (3): 5 